\title{
FUNÇÕES CONTEMPORÂNEAS DO ENSINO DE HISTÓRIA NO ENSINO MÉDIO DE CAMPO MOURÃO - PR: A PERSPECTIVA DE ESTUDANTES
}

\section{CONTEMPORARY FUNCTIONS OF HIGH SCHOOL HISTORY TEACHING IN THE CITY OF CAMPO MOURÃO - PR: THE STUDENT PERSPECTIVE}

\begin{abstract}
Ricardo Marques de Mello ${ }^{1}$
RESUMO: Neste artigo apresento resultados de pesquisa desenvolvida entre 2015 e 2017 no município de Campo Mourão, PR, a respeito da perspectiva de estudantes sobre o ensino de história. Metodologicamente, apliquei questionário com 8 questões fechadas e 3 abertas a todos os estudantes do terceiro ano do ensino médio nos Colégios do referido município. Posteriormente, os dados foram organizados no software Survey Monkey® a fim de gerar gráficos e informações sistematizadas. Os resultados gerais indicam que os estudantes: a) gostam e consideram relevante estudar história; b) estudam pouco se não forem solicitados pelos professores; c) avaliam que a quantidade de aulas por semana é inadequada; d) concordam parcialmente sobre o uso do conhecimento histórico em seu dia a dia; e) classificam a história como a terceira disciplina mais importante entre todas do sistema escolar; f) têm afeição pelo professor e o consideram competente; g) associam o estudo da história à função de conhecer o passado, compreender o presente e aprender com os erros cometidos; h) desejam aulas mais dinâmicas e práticas, sobretudo com inserção de recursos audiovisuais e visitas a locais históricos; i) e relacionam aplicabilidade do ensino de história à aprovação em certames, debates entre amigos e familiares.
\end{abstract}

PALAVRAS-CHAVE: história (ensino médio); estudo e ensino; pesquisa quantitativa.

ABSTRACT: In this article I present results of research developed between 2015 and 2017 in the city Campo Mourão, PR, about students perspective on the teaching of history. Methodologically, I applied a questionnaire with 8 closed and 3 open questions to all students of the third year of high school. Subsequently, the data were organized in Survey Monkey® software to generate graphs and systematized information. The overall conclusions indicate that students: a) like and consider relevant to study history; b) study little if not requested by the teachers; c) evaluate that the amount of classes per week is inadequate; d) partially agree on the use of historical knowledge in

\footnotetext{
* Pesquisa desenvolvida na Universidade Estadual do Paraná, campus de Campo Mourão.

${ }^{1}$ Doutor em História pela Universidade de Brasília. Professor da Universidade Estadual do Paraná, campus de Campo Mourão; Professor do Mestrado Acadêmico em História Pública e do Mestrado Profissional em Ensino de História na mesma instituição. E-mail: ricardo.rmm@gmail.com
} 
their daily lives; e) classify history as the third most important discipline in the school system; f) have appreciation for the teacher and consider him competent; g) associate the study of history with the function of knowing the past, understanding the present and learning from past mistakes; h) crave more dynamic and practical classes, especially with the insertion of audiovisual resources and visits to historical sites; i) and link the applicability of history teaching to the approval of fairs, debates between friends and family.

KEYWORDS: history (high school); study and teaching; quantitative research.

O mundo inteiro virou de cabeça pra baixo, mas uma coisa permanece a mesma: as crianças não sabem história

Sam Wineburg (2001: 06).

Neste artigo apresento resultados de pesquisa desenvolvida entre 2015 e 2017 no município de Campo Mourão, PR, acerca do ensino de história no nível médio. O objetivo inicial era contrapor as funções atribuídas ao ensino de história presentes em documentos oficiais àquelas expressas por estudantes $\mathrm{e}$ professores e publicar os resultados em um artigo. No entanto, a pesquisa como um todo gerou um superávit informacional, obrigando-me a dividir os dados em três textos: o primeiro, em que apresento as respostas de estudantes; outro a respeito da perspectiva dos professores; e um terceiro em que realizo um contraponto entre as respostas de estudantes e professores ao que recomendam os documentos oficiais. Embora o texto que ora exponho seja inteligível e tenha unidade em si, ele é, por conseguinte, a primeira parte dessa tríade.

\section{Por que pesquisar e problematizar as funções do ensino de história}

O ensino de história e, especificamente, suas serventias para a formação dos educandos têm recebido certa atenção de pesquisadores nos últimos anos. Entre os motivos que impulsionam esse interesse, dois deles são basilares: uma autorreflexão questionadora a respeito dos limites e possibilidades epistêmicas da historiografia; e as mudanças sociais do presente, que redundam em novas demandas para a produção do conhecimento histórico. Somam-se a esses dois um terceiro, específico do ambiente escolar, e que se traduz na seguinte pergunta: o ensino de história é relevante para o mundo atual? 
O primeiro motivo - a problematização epistêmica da historiografia tem uma longa trajetória de contendas acaloradas desde o final da década de 1960. Ele fomentou, por exemplo, discussões sobre o papel da linguagem na produção de significado no discurso historiográfico (LIMA, 1989), debates acerca do descrédito das metanarrativas (LYOTARD, 1988) e litígios a respeito da cientificidade da história (GARDINER, 2004). Como se sabe, apesar do empenho e recursos investidos nas críticas direcionadas aos historiadores, poucas objeções receberam solução definitiva ou foram superadas. Com o passar do tempo, algumas foram aceitas, outras tornadas sem relevância ou mesmo esquecidas. Por outro lado, algumas objeções permanecem vivas e, vez em quando, reacendem o debate e reposicionam os argumentos a outras fontes e objetos. $^{2}$

O segundo motivo - mudanças sociais que originam novas demandas é uma constante. Desde a cientifização da história, o conhecimento produzido pelos historiadores resulta de demandas geradas socialmente: a história surge de uma carência de entendimento do fluxo temporal, reformula essa necessidade aos padrões academicamente aceitáveis e volta ao corpo social como uma espécie de resposta possível à carência que inicialmente promoveu a pesquisa (RÜSEN, 2001). Nacionalismo, luta de classes, questões de gênero, grupos étnicos, minorias, entre tantos outros objetos de interesse dos historiadores ao longo do último século, ilustram como a ciência da história é condicionada ao tempo e meio no qual se insere. ${ }^{3}$

O terceiro motivo - específico do ensino - é expresso em uma série de dúvidas acerca da serventia da disciplina história em sala de aula. Questões aparentemente sem pertinência, dada a suposta obviedade das respostas, são recolocadas em pauta, tais como: é possível compreender melhor o presente

\footnotetext{
${ }^{2}$ Reflexões acerca das condições da produção cognitiva da historiografia a acompanham desde sua cientifização no século XIX. No entanto, elas têm se avolumado a partir do final da década de 1960, como nos trabalhos de Hayden White (1995; 2001) e Michel Foucault $(2008$; 2013). Em períodos de questionamentos mais incisivos, que beiram à crise disciplinar, tais reflexões se tornam mais frequentes e mais suscetíveis a críticas exógenas, como no momento em que estamos vivendo. Ver também: (BERBERT, 2016).

${ }^{3}$ A relação entre a ciência da história e as demandas oriundas da sociedade já foi ressaltada por muitos autores. Vale lembrar aqui obras de diferentes tradições e contextos, como as de Marc Bloch (2001), Hayden White (2001) e Jörn Rüsen (2001).
} 
estudando história? As funções atribuídas ao ensino de história, como tolerância e respeito à diversidade, são exequíveis? É possível ensinar alguém a pensar historicamente? O ensino de história forma cidadãos mais cônscios de seus direitos e deveres dentro de uma ética desejável? É a história um saber ensinável? ${ }^{4}$ Essas e muitas outras questões capciosas exigem respostas que fujam dos lugares comuns, de apelações a teóricos que por si só legitimariam uma saída, de soluções emotivas e, sobretudo, de respostas sem a devida validação.

Mais do que enunciar quais as funções do ensino de história, portanto, é necessário enfrentar a difícil tarefa de demonstrar que elas são realizáveis, possíveis de serem alcançadas. Nesse sentido, parece-me que estão surgindo novos instrumentos de investigação a fim de manejar categorias e conceitos, executar pesquisas de aferição, testar, problematizar, debater e reafirmar ou ressignificar as funções atribuídas ao ensino de história, seja para legitimar a sua manutenção ou propor um ensino mais consentâneo ao conjunto de circunstâncias atuais. ${ }^{5}$

Evidentemente, reconheço as implicações negativas que uma perspectiva como essa pode ter. "Aferir" o saber histórico de estudantes do ensino fundamental II e médio pode parecer um contrassenso a uma área marcada pelas várias possibilidades interpretativas, que raramente produz respostas categóricas e que se pauta na problematização de continuidades e descontinuidades como norte para lidar com determinados temas em sala de aula: ensino de história e pesquisas pragmáticas nem sempre se harmonizam (CERRI, 2016).

Não obstante, considero que as pesquisas de aferição sobre o ensino de história podem proporcionar alguns benefícios. Entre eles, vou mencionar quatro: $1^{\circ}$ ) trazer à tona o debate sobre as funções do ensino de história no mundo contemporâneo com apoio em material empírico, com tantos discursos desconexos e infundados sobre essa disciplina, é importante para que reflexões

\footnotetext{
${ }^{4}$ Sobre essa última questão, ver: MELLO, 2019.

${ }^{5}$ Esforços têm sido dedicados nesse sentido. Ressalto os trabalhos de Calderon; Cerri; Rosso (2016), Barom; Cerri (2018), Calmi; Cerri; Mistura (2018); REIS (2019).
} 
teóricas e dados quantitativos sejam articulados a fim de embasar a discussão; $2^{\circ}$ ) estimular a relação de conformidade entre o que se executa no "chão da escola" e o que se espera alcançar. Essa relação pode esclarecer princípios e propósitos da disciplina, bem como aumentar o grau de consciência dos professores sobre o que, como e por que fazem o que estão fazendo; $3^{\circ}$ ) aprimorar os próprios instrumentos de pesquisas dessa natureza. Com o passar do tempo, talvez seja possível criar índices, ferramentas e procedimentos mais precisos a partir dos quais se consiga diagnosticar e prognosticar novos rumos ao ensino de história; e $4^{\circ}$ ) incluir nessa discussão estudantes e professores da rede básica para ampliar os pontos de vista, já que boa parte das respostas que temos a respeito das funções do ensino de história está concentrada em obras renomadas de filósofos, historiadores e educadores, que, oportunamente, são apropriadas pelos elaboradores de manuais e de documentos da área.

É, portanto, com base nesses benefícios em potencial que apresento os resultados parciais de pesquisa sobre as funções do ensino de história. Meu recorte espacial foi o município de Campo Mourão, PR; o temporal: entre 2015 e 2017; minha metodologia predominante foi a aplicação de questionário a estudantes e a quantificação dos dados; as fontes foram alunos do terceiro ano do ensino médio.

O local, o instrumento de pesquisa e os recursos metódicos

O município de Campo Mourão está situado no centro-oeste paranaense, a 460 quilômetros de Curitiba. Com aproximadamente 100 mil habitantes, é uma cidade jovem, oficialmente fundada em 1947. Atualmente, sua economia está concentrada na agricultura e no comércio. No ensino, tem mais de 20 escolas municipais do fundamental I, quase o mesmo número de instituições voltadas aos ensinos fundamental II e médio e 5 instituições presenciais de ensino superior, 2 públicas e 3 particulares.

A pesquisa que desenvolvi consistiu na aplicação de um questionário em todas as escolas estaduais e particulares, especificamente no terceiro ano do 
ensino médio. ${ }^{6}$ A escolha dessa série justifica-se por ser o último ano da formação básica escolar, o que me permitiu pressupor que, por estar em vias de finalização, o estudante desse período, em tese, tem melhores condições de avaliar o ensino de história e, também, porque já alcançou o que dele se espera para este nível educacional. Os Colégios foram os seguintes:

- Colégio Estadual Prefeito Antônio Teodoro Oliveira;

- Colégio Estadual Marechal Rondon;

- Colégio Estadual Unidade Polo;

- Colégio Estadual de Campo Mourão;

- Centro Estadual de Educação Profissional Agrícola de Campo Mourão;

- Colégio Estadual Alvorada;

- Colégio Estadual Doutor Osvaldo Cruz;

- Colégio Estadual Dom Bosco;

- Colégio Estadual Vinícius de Moraes;

- Colégio Estadual Professora Ivone Soares Castanharo;

- Colégio Estadual Novo Horizonte;

- Colégio Estadual Professor Darcy José Costa;

- Colégio Estadual do Campo Professor Jaelson Biacio;

- Colégio Santa Cruz;

- Colégio Adventista;

- Colégio Integrado.

O quadro abaixo apresenta a quantidade de estudantes do terceiro ano do ensino médio presentes no dia da pesquisa em cada colégio:

Quadro 1- Instituições de Ensino e estudantes dos terceiros anos do município de Campo Mourão em 2016

\begin{tabular}{|l|l|l|}
\hline Instituição de Ensino & Número de alunos & Percentual \\
\hline & & \\
\hline Darcy Costa - Matutino & 18 & $2,62 \%$ \\
\hline Darcy Costa - Noturno & 15 & $2,19 \%$ \\
\hline Integrado & 42 & $6,12 \%$ \\
\hline Santa Cruz & 43 & $6,25 \%$ \\
\hline Adventista & 40 & $5,83 \%$ \\
\hline
\end{tabular}

\footnotetext{
${ }^{6}$ Ficaram de fora da pesquisa aquelas instituições cujo ensino médio era técnico (por que a carga horária da disciplina de história é diferente) e o Colégio Sigma, instituição privada que preferiu não participar da pesquisa. No cômputo total dos alunos matriculados no município, os estudantes do referido colégio perfazem menos de $5 \%$, o que, em termos quantitativos, não compromete os resultados alcançados.
} 


\begin{tabular}{|l|l|l|}
\hline Antonio Teodoro de Oliveira & 48 & $7 \%$ \\
\hline Ivone Castanharo - Matutino & 47 & $6,85 \%$ \\
\hline Ivone Castanharo - Noturno & 12 & $1,75 \%$ \\
\hline Alvorada & 9 & $1,31 \%$ \\
\hline Novo Horizonte & 21 & $3,06 \%$ \\
\hline Oswaldo Cruz - Matutino & 27 & $3,94 \%$ \\
\hline Oswaldo Cruz - Noturno & 11 & $1,60 \%$ \\
\hline Dom Bosco - Matutino & 21 & $3,06 \%$ \\
\hline Dom Bosco - Noturno & 27 & $3,94 \%$ \\
\hline Unidade Polo - Matutino & 50 & $7,29 \%$ \\
\hline Unidade Polo - Noturno & 28 & $4,08 \%$ \\
\hline Vinícius de Morais & 10 & $1,46 \%$ \\
\hline Jaelson Biácio & 5 & $0,73 \%$ \\
\hline Colégio Agrícola & 46 & $6,71 \%$ \\
\hline Marechal Rondon & 122 & $17,78 \%$ \\
\hline Colégio Estadual - Matutino & 24 & $3,50 \%$ \\
\hline Colégio Estadual - Noturno & 21 & $3,06 \%$ \\
\hline & & \\
\hline Total & $\mathbf{6 8 7}$ & $\mathbf{1 0 0 \%}$ \\
\hline
\end{tabular}

O questionário aplicado é o que está abaixo:

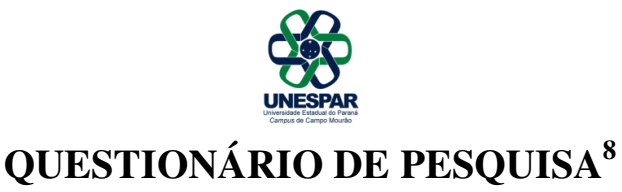

Colégio:

Data:

1) Sexo: ( ) masculino; ( ) feminino.

2) Período: ( ) matutino; ( ) vespertino; ( ) noturno.

Responda as questões abaixo de acordo com o grau de concordância ou discordância que você tem em relação a cada uma das afirmações.

3) Você gosta de estudar História?

\footnotetext{
${ }^{7}$ De acordo com informações dos professores que atuavam no dia e horário da aplicação do questionário nas escolas públicas, naquele exato momento havia um número considerável de ausentes/ evadidos. Somadas todas as informações dessa natureza, o número de ausentes e/ou desistentes, de acordo com os professores, gira em torno de $30 \%$ nas escolas públicas e $7 \%$ nas particulares.

${ }^{8}$ Este questionário é um dos instrumentos da pesquisa "As Funções do Conhecimento Histórico no Ensino Médio de História em Campo Mourão: 2014-2016”, coordenada pelo professor Adjunto Ricardo Marques de Mello, que integra o Colegiado de História da Universidade Estadual do Paraná, campus de Campo Mourão.
} 
( ) Concordo plenamente

( ) Concordo parcialmente

( ) Discordo parcialmente

( ) Discordo plenamente

( ) Não sei responder.

4) Você estuda História mesmo que o seu professor não lhe peça?

( ) Concordo plenamente

( ) Concordo parcialmente

( ) Discordo parcialmente

( ) Discordo plenamente

( ) Não sei responder.

5) Você considera importante estudar História?

( ) Concordo plenamente

( ) Concordo parcialmente

( ) Discordo parcialmente

( ) Discordo plenamente

( ) Não sei responder.

6) A quantidade de aulas de História que você tem por semana é suficiente para você aprender os conteúdos da matéria de História.
( ) Concordo plenamente
( ) Concordo parcialmente
( ) Discordo parcialmente
( ) Discordo plenamente
( ) Não sei responder.

7) Você já usou ou usa algum conhecimento das aulas de História no seu dia a dia?

( ) Concordo plenamente

( ) Concordo parcialmente

( ) Discordo parcialmente

( ) Discordo plenamente

( ) Não sei responder.

8) Se você pudesse classificar a importância que cada disciplina ensinada na escola tem para você, qual seria a posição da História?
( ) $1^{\circ}$ lugar
( ) $2^{\circ}$ lugar
( ) $3^{\circ}$ lugar
( ) $4^{\circ}$ lugar
( ) $5^{\circ}$ lugar
( ) $6^{\circ}$ lugar
( ) $7^{\circ}$ lugar
( ) $8^{\circ}$ lugar
( ) $9^{\circ}$ lugar
( ) último lugar

9) Você gosta do seu professor de História?

( ) Concordo plenamente

( ) Concordo parcialmente

( ) Discordo parcialmente

( ) Discordo plenamente

( ) Não sei responder. 
10) Seu/sua professor(a) de História domina e conhece os assuntos de História que ele(a) ensina em sala de aula.

( ) Concordo plenamente

( ) Concordo parcialmente

( ) Discordo parcialmente

( ) Discordo plenamente

( ) Não sei responder.

11) Em sua opinião, para que serve estudar História? Explique por quê.

12) Em sua opinião, como as aulas de História poderiam ser melhores?

13) Cite um caso em que o conhecimento da História foi importante para você.

Da terceira à décima questão (com exceção da oitava), todas as perguntas e as respostas possíveis seguiram a Escala de Likert, permitindo aos respondentes cinco opções: concordo plenamente; concordo parcialmente; discordo parcialmente; discordo plenamente; não sei responder. Criada pelo estadunidense Rensis Likert, a referida escala pretende aferir o grau de concordância/discordância do perguntado a um item. A ideia consiste em identificar qual o posicionamento do indivíduo entre $100 \%$ (concordo plenamente) e $0 \%$ (discordo plenamente). Nesse sentido, a opção concordo parcialmente equivaleria a algo próximo a $75 \%$ de concordância em relação ao item, ao passo que a opção discordo parcialmente equivaleria a algo próximo a $25 \%$.

Todavia, há muitas críticas em relação a este modelo e sua idealização. Um dos motivos de desaprovação reside na assertiva de que nem todos os entrevistados compreendem essa equivalência. Além disso, para uma parte diminuta deles, não haveria muitas diferenças entre concordo parcialmente e discordo parcialmente. Para minimizar esses efeitos negativos do uso da Escala de Likert, ao me apresentar às turmas em que apliquei os questionários, realizei uma breve explicação do instrumento da pesquisa e coloquei-me à disposição para sanar eventuais dúvidas. Não obstante, reconheço que o referido método pode apresentar problemas e capta o campo de observação com certo grau de imprecisão. Após a aplicação dos questionários, todos os dados foram transferidos ao software Survey Monkey® a fim de sistematizá-los.

Apresentação e análise dos dados 
No total, 687 questionários foram respondidos. Destes, 563 de escolas públicas $(82 \%)$ e 124 de escolas particulares (18\%). No que se refere ao período em que estavam matriculados, $573(83,5 \%)$ alunos estudavam no turno matutino e $114(16,5 \%)$ no período da noite. Em relação ao gênero, preponderância de mulheres: 363 pessoas do sexo feminino (52,9\%), 323 do masculino (47\%) e $1(0,15 \%)$ não respondeu.

Após as primeiras perguntas - relativas ao gênero e ao período de estudo - seguiram-se as questões sobre o ensino de história. A pergunta número três do questionário, "Você gosta de estudar história?", teve os seguintes resultados:

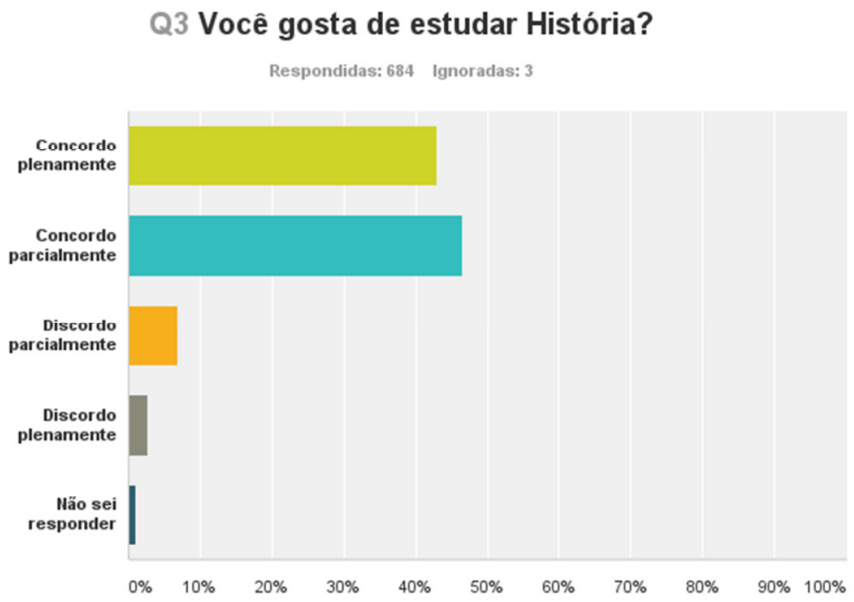

Quadro 2 - "Você gosta de estudar história"?

\begin{tabular}{|l|l|l|}
\hline $\begin{array}{c}\text { Resposta } \\
\text { escolhida }\end{array}$ & $\begin{array}{l}\text { Número de } \\
\text { respondentes }\end{array}$ & Percentual \\
\hline & & \\
\hline Concordo plenamente & 294 & $42,98 \%$ \\
\hline Concordo parcialmente & 318 & $46,49 \%$ \\
\hline Discordo parcialmente & 47 & $6,87 \%$ \\
\hline Discordo plenamente & 18 & $2,63 \%$ \\
\hline Não sei responder & 7 & $1,02 \%$ \\
\hline & & \\
\hline TOTAL & 684 & $100 \%$ \\
\hline
\end{tabular}


Ao somarmos a opção "Concordo plenamente" com "Concordo parcialmente" podemos concluir que a disciplina de história é bem quista pelos estudantes. Apenas $10,52 \%$ deles não se aprazem com os estudos dos seres humanos no tempo. Entretanto, se cruzarmos os resultados desse item com os da próxima pergunta, "Você estuda História mesmo que o seu professor não lhe peça?”, emerge uma dúvida: se há satisfação em estudar história, por que essa ação não se estende para fora do ambiente escolar? Vejamos os resultados:

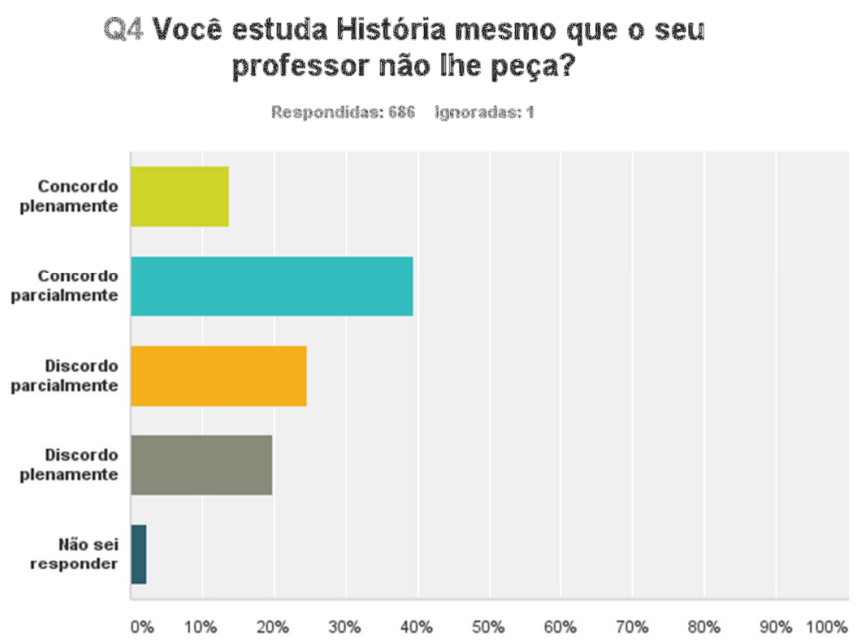

Quadro 3 - "Você estuda história mesmo que seu professor não lhe peça?"

\begin{tabular}{|l|l|l|}
\hline Resposta escolhida & $\begin{array}{l}\text { Número de } \\
\text { respondentes }\end{array}$ & Percentual \\
\hline & & \\
\hline & & \\
\hline Concordo plenamente & 95 & $13,85 \%$ \\
\hline Concordo parcialmente & 270 & $39,36 \%$ \\
\hline Discordo parcialmente & 169 & $24,64 \%$ \\
\hline Discordo plenamente & 136 & $19,83 \%$ \\
\hline Não sei responder & 16 & $2,33 \%$ \\
\hline & & \\
\hline TOTAL & 686 & $100 \%$ \\
\hline
\end{tabular}


Se as opções "Concordo plenamente" e "Concordo parcialmente" na pergunta anterior (questão 3) totalizavam quase $90 \%$ das respostas, aqui as duas não alcançam $54 \%$. Esse é um bom indicativo para que se reflita sobre os fatores que influem, positiva e negativamente, no estudo da história fora da escola. Seria esse um problema específico da disciplina história ou uma característica dos estudantes pesquisados? Qual é o elo que falta para ligar a história escolar aos fenômenos diários que, por natureza, estão repletos de história? Para reforçar a dúvida, a pergunta "Você considera importante estudar História?" resultou em dados que demonstram que expressivos 96,8\% dos estudantes concordam com ela plena ou parcialmente. Essa é uma relação estranha: 90\% gostam de estudar história; 96\% consideram seu estudo importante; mas apenas $53 \%$ o realizam sem que haja um pedido formal do professor dessa matéria.

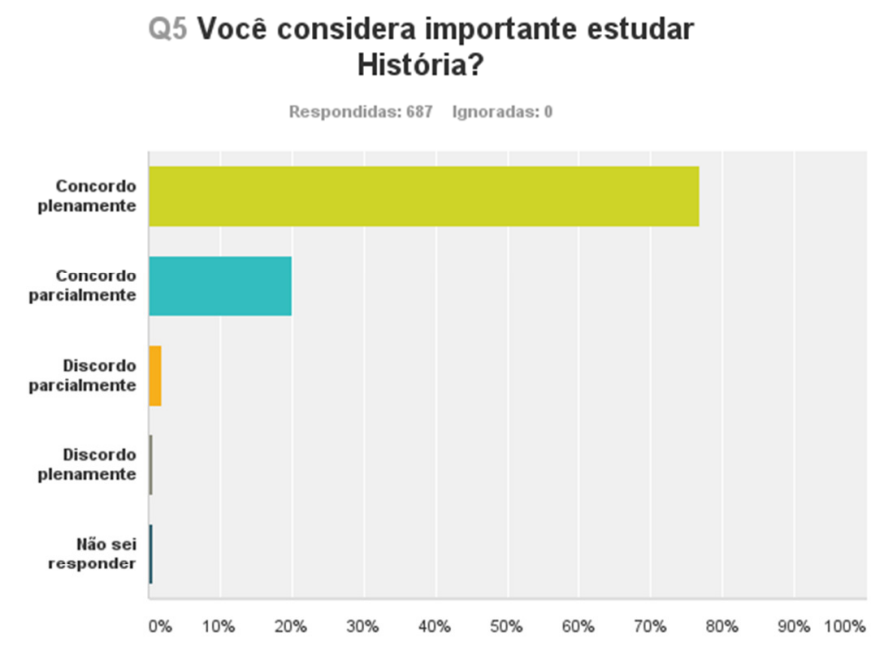

Quadro 4 - "Você considera importante estudar história?"

\begin{tabular}{|l|l|l|}
\hline Resposta escolhida & $\begin{array}{l}\text { Número de } \\
\text { respondentes }\end{array}$ & Percentual \\
\hline & & \\
\hline Concordo plenamente & 528 & $76,86 \%$ \\
\hline Concordo parcialmente & 137 & $19,94 \%$ \\
\hline Discordo parcialmente & 13 & $1,89 \%$ \\
\hline
\end{tabular}




\begin{tabular}{|l|l|l|}
\hline Discordo plenamente & 5 & $0,73 \%$ \\
\hline Não sei responder & 4 & $0,58 \%$ \\
\hline & & \\
\hline TOTAL & 687 & $100 \%$ \\
\hline
\end{tabular}

Com resultados um pouco mais bem distribuídos, a questão 6 inquiria: "A quantidade de aulas de História que você tem por semana é suficiente para você aprender os conteúdos da matéria de História?". Nesse caso, devo mencionar que as escolas ofertavam 2 aulas semanais da disciplina. Os resultados entre as alternativas, como se pode perceber, são similares, com pequena margem de preponderância para a opção discordo plenamente.

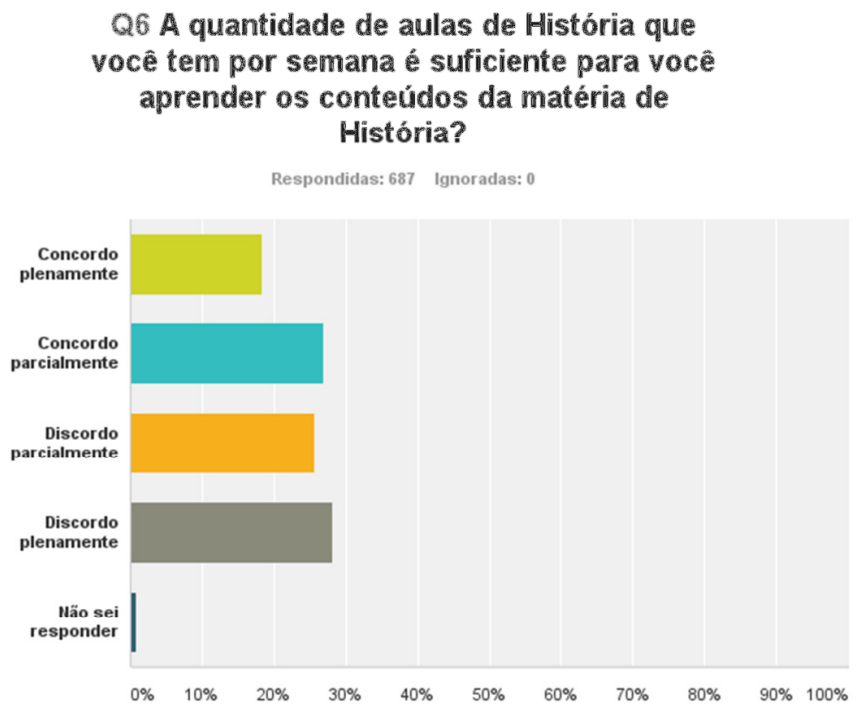

Quadro 5 - "A quantidade de aulas de história que você tem por semana é suficiente para você aprender os conteúdos da matéria de História?"

\begin{tabular}{|l|l|l|}
\hline Resposta escolhida & $\begin{array}{l}\text { Número de } \\
\text { respondentes }\end{array}$ & Percentual \\
\hline & & \\
\hline Concordo plenamente & 126 & $18,34 \%$ \\
\hline Concordo parcialmente & 185 & $26,93 \%$ \\
\hline Discordo parcialmente & 176 & $25,62 \%$ \\
\hline Discordo plenamente & 194 & $28,24 \%$ \\
\hline Não sei responder & 6 & $0,87 \%$ \\
\hline & & \\
\hline TOTAL & 687 & $100 \%$ \\
\hline
\end{tabular}


Os resultados da questão 7, por outro lado, são um pouco mais díspares. À pergunta "Você já usou ou usa algum conhecimento das aulas de História no seu dia a dia?", os alunos responderam da seguinte forma:

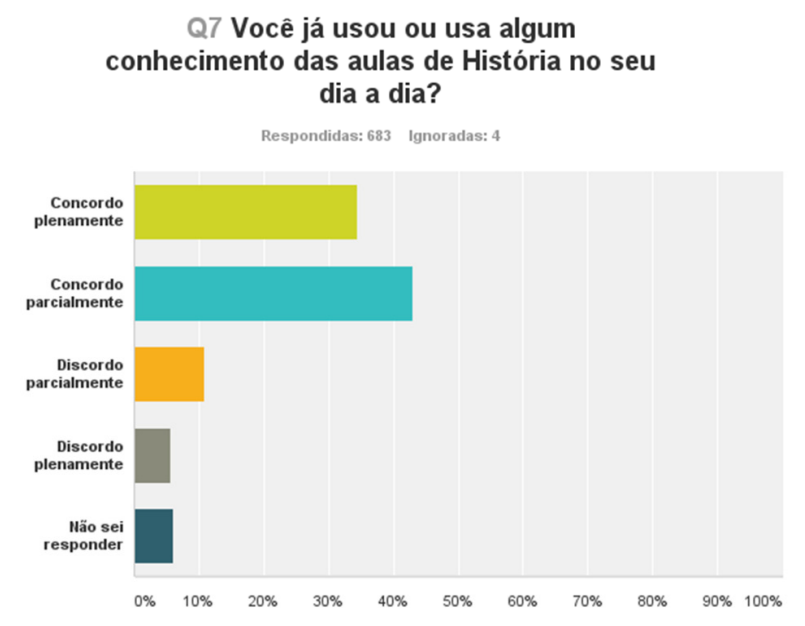

Quadro 6 - "Você já usou ou usa algum conhecimento das aulas de História no seu dia a dia?"

\begin{tabular}{|l|l|l|}
\hline Resposta escolhida & $\begin{array}{l}\text { Número de } \\
\text { respondentes }\end{array}$ & Percentual \\
\hline & & \\
\hline Concordo plenamente & 235 & $34,41 \%$ \\
\hline Concordo parcialmente & 294 & $43,05 \%$ \\
\hline Discordo parcialmente & 74 & $10,83 \%$ \\
\hline Discordo plenamente & 39 & $5,71 \%$ \\
\hline Não sei responder & 41 & $6,00 \%$ \\
\hline & & \\
\hline TOTAL & 683 & $100 \%$ \\
\hline
\end{tabular}

De acordo com as respostas, aproximadamente $77 \%$ dos estudantes concordam plena ou parcialmente com a pergunta. Por ser esta uma questão fechada, não foi possível, por exemplo, identificar o que cada um compreende por conhecimento histórico e o tipo de uso possível. A última questão aberta do questionário, "Cite um caso em que o conhecimento da História foi importante para você”, retoma, em certo sentido, essa dúvida. Veremos adiante os resultados. 
A questão 8 extrapolou um pouco as dúvidas sobre a história enquanto disciplina e exigiu dos estudantes uma perspectiva comparativa com as demais matérias escolares. A pergunta era: "Se você pudesse classificar a importância que cada disciplina ensinada na escola tem para você, qual seria a posição da História?" Os resultados foram:

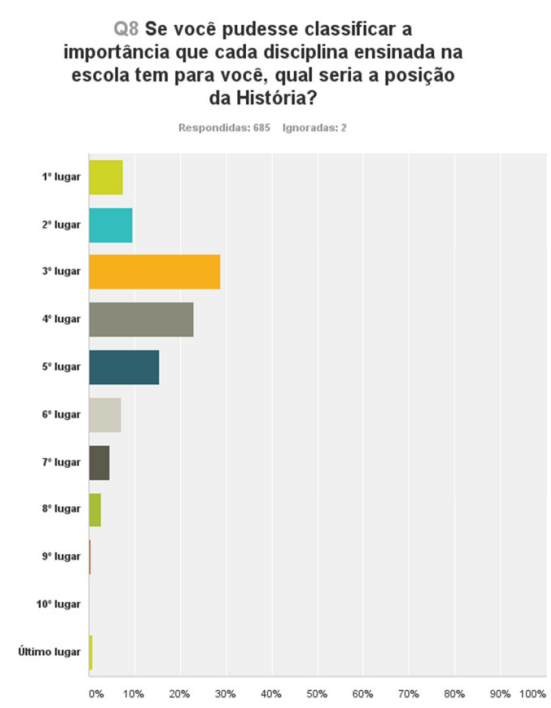

Quadro 7 - "Se você pudesse classificar a importância que cada disciplina ensinada na escola tem para você, qual seria a posição da História?"

\begin{tabular}{|l|l|l|}
\hline Resposta escolhida & $\begin{array}{l}\text { Número } \\
\text { respondentes }\end{array}$ & Percentual \\
\hline & & \\
\hline $1^{\circ}$ lugar & 52 & $7,59 \%$ \\
\hline $2^{\circ}$ lugar & 66 & $9,64 \%$ \\
\hline $3^{\circ}$ lugar & 197 & $28,76 \%$ \\
\hline $4^{\circ}$ lugar & 158 & $23,07 \%$ \\
\hline $5^{\circ}$ lugar & 106 & $15,47 \%$ \\
\hline $6^{\circ}$ lugar & 48 & $7,01 \%$ \\
\hline $7^{\circ}$ lugar & 31 & $4,53 \%$ \\
\hline $8^{\circ}$ lugar & 18 & $2,63 \%$ \\
\hline $9^{\circ}$ lugar & 3 & $0,44 \%$ \\
\hline $10^{\circ}$ lugar & 0 & $0 \%$ \\
\hline Último lugar & 6 & $0,88 \%$ \\
\hline TOTAL & 685 & $100 \%$ \\
\hline
\end{tabular}


Mais da metade das respostas situaram a disciplina História entre a terceira e a quarta posição. Essa questão está ligada com a que vem em seguida, que deslocou o foco da disciplina para a figura docente: "Você gosta do seu Professor de História?". As respostas indicam que 76,28\% concordam plenamente e 16,69\% concordam parcialmente. As duas opções somadas totalizam quase 93\%, o que é um resultado expressivo, sobretudo se considerarmos que a relação de afetividade pode ter vínculo imediato com a aprendizagem.

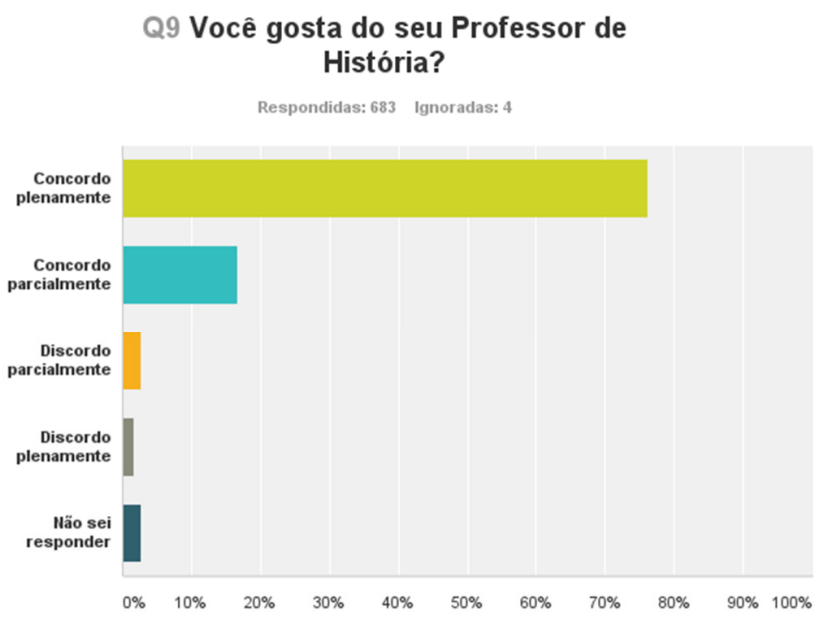

Quadro 8 - "Você gosta do seu Professor de História?"

\begin{tabular}{|l|l|l|}
\hline Resposta escolhida & $\begin{array}{l}\text { Número de } \\
\text { respondentes }\end{array}$ & Percentual \\
\hline & & \\
\hline Concordo plenamente & 521 & $76,28 \%$ \\
\hline Concordo parcialmente & 114 & $16,69 \%$ \\
\hline Discordo parcialmente & 18 & $2,64 \%$ \\
\hline Discordo plenamente & 11 & $1,61 \%$ \\
\hline Não sei responder & 19 & $2,78 \%$ \\
\hline & & \\
\hline TOTAL & 683 & $100 \%$ \\
\hline
\end{tabular}

Na última questão objetiva do questionário, "Seu/sua Professor(a) de História domina e conhece os assuntos de História que ele(a) ensina em sala de 
aula?", dois dados se destacam. Surpreendentemente, a relação entre gostar do professor (questão anterior) e considerá-lo qualificado em seu ofício não é, obrigatoriamente, necessária. Se compararmos a opção "Concordo plenamente" da pergunta anterior (questão 9) com a abaixo, é flagrante a diferença: 76,28\% gostam do professor, ao passo que 90,23\% o consideram capacitado. Assim, a conexão entre relação afetiva e competência não é automática. Apesar de aproximadamente $23 \%$ dos estudantes não concordarem plenamente sobre gostar do seu professor de história, menos de $10 \%$ não o consideram plenamente capaz. A segunda informação a ser sublinhada diz respeito ao percentual relativo aos estudantes que discordaram parcial ou plenamente acerca do domínio cognitivo do seu professor de História: diminutos 1,61\%.

Q10 Seu/sua Professor(a) de História domina e conhece os assuntos de História que ele(a) ensina em sala de aula? Respondidas: 686 Ignoradas: 1

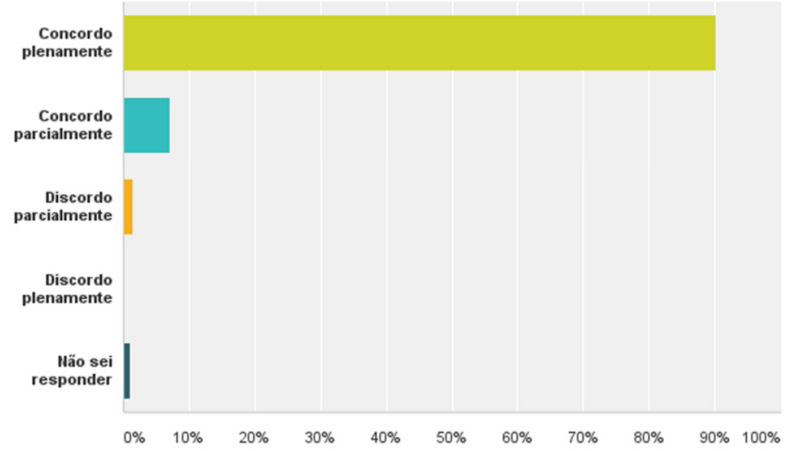

Quadro 9 - "Seu/sua Professor(a) de História domina e conhece os assuntos de História que ele(a) ensina em sala de aula?"

\begin{tabular}{|l|l|l|}
\hline Resposta escolhida & $\begin{array}{l}\text { Número de } \\
\text { respondentes }\end{array}$ & Percentual \\
\hline & & \\
\hline Concordo plenamente & 619 & $90,23 \%$ \\
\hline Concordo parcialmente & 49 & $7,14 \%$ \\
\hline Discordo parcialmente & 10 & $1,46 \%$ \\
\hline Discordo plenamente & 1 & $0,15 \%$ \\
\hline Não sei responder & 7 & $1,02 \%$ \\
\hline & & \\
\hline TOTAL & 686 & $100 \%$ \\
\hline
\end{tabular}


Para além das questões fechadas, que nos trazem indicativos interessantes, mas também muitas dúvidas, o questionário aplicado continha três questões abertas. Todas com respostas muito variadas, o que, de certo modo, tornou a sistematização mais difícil e subjetiva. A primeira questão aberta era: "Em sua opinião, para que serve estudar História? Explique por quê". Com base nas respostas, foi possível reuni-las em tópicos. ${ }^{9}$ Os resultados são os seguintes:

Quadro 10 - "Em sua opinião, para que serve estudar História? Explique por quê."

\begin{tabular}{|l|l|l|}
\hline $\begin{array}{l}\text { Questão: “Em sua opinião, para que serve estudar } \\
\text { História? Explique por quê." } \\
\text { (673 campos preenchidos; 14 vazios) }\end{array}$ & Quantidade & Percentual \\
\hline & & \\
\hline Aumentar o conhecimento sobre o passado & 405 & $60,1 \%$ \\
\hline Compreender melhor o presente & 231 & $34,3 \%$ \\
\hline Aprender com os erros cometidos & 72 & $10,7 \%$ \\
\hline Conhecer a evolução das sociedades & 60 & $8,9 \%$ \\
\hline $\begin{array}{l}\text { Ampliar visões, ideias, se inspirar, abrir a mente, } \\
\text { ter mais conhecimento }\end{array}$ & 44 & $6,5 \%$ \\
\hline Conhecer nosso país & 39 & $5,8 \%$ \\
\hline Aplicar para melhorar o presente & 29 & $4,3 \%$ \\
\hline Passar em certames, de ano escolar, e ir bem no ENEM & 27 & $4,0 \%$ \\
\hline Estabelecer relações entre passado, presente e futuro & 27 & $4,0 \%$ \\
\hline Estudar pessoas e/ou fatos marcantes & 25 & $3,7 \%$ \\
\hline Base para a construção de argumentos & 17 & $2,5 \%$ \\
\hline Para antecipar o futuro & 10 & $1,5 \%$ \\
\hline $\begin{array}{l}\text { Valorizar o presente porque a sobrevivência no } \\
\text { passado era difícil }\end{array}$ & 8 & $1,2 \%$ \\
\hline Formação de pensamento crítico & 7 & $1,0 \%$ \\
\hline Base para outras matérias/disciplinas & 5 & $0,7 \%$ \\
\hline Não sei opinar/quase nada & 2 & $0,3 \%$ \\
\hline
\end{tabular}

\footnotetext{
${ }^{9}$ Como as respostas dos estudantes podiam conter mais de um tópico, o número de respostas
} ultrapassa o número de respondentes e o percentual, por consequência, excede $100 \%$. 
A função mais mencionada, "Aumentar o conhecimento sobre o passado" (60,1\%), foi, amiúde, informada de maneira isolada, ou seja, como objetivo final da disciplina. É como se conhecer o passado tivesse finalidade em si mesmo, sem vínculo aparente com o mundo atual. A segunda resposta mais citada, "Compreender melhor o presente" (34,3\%), por sua vez, vai em direção oposta: o estudo do passado como meio. O passado, nesse caso, torna-se um caminho para ir além dele próprio. A terceira função mais anotada está ligada ao caráter pedagógico que o estudo do passado pode exercer: "Aprender com os erros cometidos" (10,7\%). Já a função "Conhecer a evolução das sociedades" foi citada por $8,9 \%$ dos respondentes. As quatro primeiras funções atribuídas ao ensino de história pelos próprios estudantes têm relações diretas com tradições historiográficas e com funções da história que precedem o ensino escolar da história. Elas expressam diferentes posições de historiadores historicistas, annalistes, de filósofos da história e do topoi da historia magistra vitae. As demais respostas expressam bem a variedade de serventias que o estudo da história pode ter: de funções mais abstratas ("Ampliar visões, ideias, se inspirar, abrir a mente, ter mais conhecimento": 6,5\%), a utilidades mais pragmáticas (como no tópico "Aplicar para melhorar o presente": 4,3\%), as funções do ensino escolar da história são adaptadas às circunstâncias e desejos individuais e contextuais. Por fim, devo destacar que apenas $0,3 \%$ não souberam ou não identificaram alguma serventia para essa matéria escolar.

A segunda questão aberta era: "Em sua opinião, como as aulas de História poderiam ser melhores?" Como era previsível, a diversidade de respostas a esta questão foi a maior entre as três abertas. Muitos aspectos merecem atenção. O primeiro deles é que $67,1 \%$ dos alunos sugeriram algum tipo de dinamicidade distinta da que é praticada atualmente ao concederem respostas alocadas nos tópicos "Usar mais recursos audiovisuais"; "Visitar lugares como cidades históricas e museus"; "Aulas mais dinâmicas"; "Aulas mais práticas (objetos, maquetes, teatro)"; "Mais interação entre Professor/ aluno"; "Mais diálogos e debates sobre o conteúdo". A propósito, a palavra "dinâmica" e suas correlatas apareceram 94 vezes. O segundo ponto a ser 
sublinhado refere-se ao percentual de estudantes que mencionaram a necessidade de mais aulas de história por semana: $16,1 \%$. Essa é uma queixa constante de educadores, sobretudo pela incompatibilidade entre a extensão do conteúdo programático e o tempo para desenvolvê-lo a contento. Destaco ainda que para $12 \%$ dos respondentes as aulas estão boas ou ótimas, o que lhes dispensou sugestões de melhorias. A insatisfação com o comportamento de colegas ou com professores, por seu turno, somou 8,6\% e, destes, apenas 1 estudante $(0,2 \%$ do total) mencionou a necessidade do professor ser mais neutro e imparcial. As demais respostas, todas muito interessantes, podem suscitar muitas outras discussões e propostas para melhorias do ensino de história. Algumas exequíveis com pequenas mudanças; outras dependentes de ações de âmbito político-partidário. Mas todas, incluindo o gracejo espirituoso de sugerir "Rodízio de pizza, churrasco, lanche com suco", merecedoras de atenção e debate.

Quadro 11 - "Em sua opinião, como as aulas de História poderiam ser melhores?"

\begin{tabular}{|l|l|l|}
\hline $\begin{array}{l}\text { Questão: “Em sua opinião, como as aulas de História } \\
\text { poderiam ser melhores?” } \\
\text { (651 campos preenchidos; 36 vazios) }\end{array}$ & Quantidade & Percentual \\
\hline & & \\
\hline Usar mais recursos audiovisuais & 132 & $20,3 \%$ \\
\hline Visitar lugares como cidades históricas e museus & 119 & $18,3 \%$ \\
\hline Mais aulas de história por semana & 105 & $16,1 \%$ \\
\hline Aulas mais dinâmicas & 83 & $12,7 \%$ \\
\hline Nada. As aulas já são boas/ótimas & 78 & $12,0 \%$ \\
\hline Aulas mais práticas (objetos, maquetes, teatro) & 61 & $9,4 \%$ \\
\hline $\begin{array}{l}\text { Maior colaboração dos próprios alunos (participação, uso } \\
\text { da imaginação e silêncio) }\end{array}$ & 28 & $4,3 \%$ \\
\hline $\begin{array}{l}\text { Melhores professores (domínio de conteúdo; bom humor; } \\
\text { linguajar atualizado; comportamento adequado; aproveitar } \\
\text { melhor o tempo; apresentar exemplos; ser mais } \\
\text { neutro/imparcial) }\end{array}$ & 28 & $4,3 \%$ \\
\hline Mais interação entre Professor/ aluno & 21 & $3,2 \%$ \\
\hline
\end{tabular}




\begin{tabular}{|l|l|l|}
\hline Mais diálogos e debates sobre o conteúdo & 21 & $3,2 \%$ \\
\hline Mais brincadeiras e entretenimento & 19 & $2,9 \%$ \\
\hline Outros (Sem sugestão. Apenas um comentário) & 19 & $2,9 \%$ \\
\hline $\begin{array}{l}\text { Associar o conteúdo da aula ao dia a dia e/ou explicitar } \\
\text { influências do passado no presente/ mostrar aplicabilidade }\end{array}$ & 16 & $2,5 \%$ \\
\hline Diversificação temática & 14 & $2,2 \%$ \\
\hline Novas metodologias & 14 & $2,2 \%$ \\
\hline Uso mais frequente de tecnologia & 12 & $1,8 \%$ \\
\hline Mais palestras acerca de temas históricos & 10 & $1,5 \%$ \\
\hline Não sei & 9 & $1,4 \%$ \\
\hline Mais investimentos do governo e/ou escola & 9 & $1,4 \%$ \\
\hline Mais trabalhos de pesquisa/ projetos & 9 & $1,4 \%$ \\
\hline Mais história do Brasil e/ou Paraná e/ou região & 9 & $1,4 \%$ \\
\hline Outro material didático/ melhorar o material didático & 8 & $1,2 \%$ \\
\hline Os próprios alunos produzirem mais & 8 & $1,2 \%$ \\
\hline Metodologias para memorização & 7 & $1,0 \%$ \\
\hline Frequência e distribuição das aulas & 5 & $0,8 \%$ \\
\hline Mais seminários em sala de aula & 4 & $0,6 \%$ \\
\hline Rodízio de pizza, churrasco, lanche com suco & 3 & $0,5 \%$ \\
\hline Menos conteúdo & 3 & $0,5 \%$ \\
\hline Usar mais documentos & 1 & $0,5 \%$ \\
\hline Aulas mais interdisciplinares & 1 & $0,3 \%$ \\
\hline Associar conteúdo a séries, jogos e filmes atuais & 1 & $0,2 \%$ \\
\hline Diversificação de métodos de avaliação & $0,2 \%$ \\
\hline Mais teoria & 1 & $0,2 \%$ \\
\hline Explicar para que serve o conteúdo estudado & 1 & \\
\hline
\end{tabular}

A terceira questão aberta, "Cite um caso em que o conhecimento da História foi importante para você", é semelhante à questão 7: "Você já usou ou usa algum conhecimento das aulas de História no seu dia a dia?" Mas, por ser aberta, ampliou e explicitou o uso do conhecimento histórico, com, pelo menos, um caso por aluno. Evidentemente, essa questão não teve como propósito 
identificar em quê os estudantes usa o aprendizado histórico, mas, antes, objetivava conhecer no quê eles reconhecem o uso do conhecimento histórico. Não é uma diferença sutil, sobretudo por que: 1) os usos do conhecimento histórico nem sempre são discutidos em sala de aula, o que ampliaria a percepção dos educandos sobre esse tema; 2) os efeitos do ensino de história não são autônomos/ puros, i. e., um saber apropriado em uma aula de história pode, consciente ou inconscientemente, ser associado a outros saberes a fim de orientar o educando em suas representações ou ações práticas; 3) os usos do conhecimento histórico não ecoam apenas no presente do estudante. Diferentemente disso, podem ter efeitos ao longo de sua vida. As respostas da última questão foram sistematizadas no quadro abaixo:

Quadro 12 - "Cite um caso em que o conhecimento da História foi importante para você"

\begin{tabular}{|l|l|l|}
\hline $\begin{array}{l}\text { Questão: “Cite um caso em que o conhecimento da } \\
\text { História foi importante para você" } \\
\text { (592 campos preenchidos; 95 vazios) }\end{array}$ & Quantidade & Percentual \\
\hline & & \\
\hline $\begin{array}{l}\text { Em certames, avaliações escolares, Exame Nacional do } \\
\text { Ensino Médio }\end{array}$ & 154 & $26,0 \%$ \\
\hline Em diálogos e debates com amigos e parentes & 95 & $16,0 \%$ \\
\hline Na compreensão de um assunto de história geral & 80 & $13,5 \%$ \\
\hline $\begin{array}{l}\text { No aumento da consciência/conhecimento sobre o } \\
\text { passado e/ou presente/ na formação de opinião sobre o } \\
\text { mundo }\end{array}$ & 62 & $10,5 \%$ \\
\hline Na compreensão de um assunto de história do Brasil & 61 & $10,3 \%$ \\
\hline Nenhum/ não me recordo/ não sei & 47 & $7,9 \%$ \\
\hline $\begin{array}{l}\text { No uso da história como conhecimento auxiliar a outras } \\
\text { matérias escolares/atividades }\end{array}$ & 31 & $5,2 \%$ \\
\hline Na tomada de posicionamento político & 30 & $5,1 \%$ \\
\hline Na compreensão de filmes, TV, séries, jogos, livros & 25 & $4,2 \%$ \\
\hline Outros. Respostas impertinentes & 19 & $3,2 \%$ \\
\hline Em história familiar/pessoal & 19 & $3,2 \%$ \\
\hline Ao ajudar alguém & 18 & $3,0 \%$ \\
\hline Em situações do dia a dia & 18 & $3,0 \%$ \\
\hline
\end{tabular}




\begin{tabular}{|l|l|l|}
\hline Na compreensão de um tema relativo à história regional & 10 & $1,7 \%$ \\
\hline Quando sou questionado e sei responder & 9 & $1,5 \%$ \\
\hline Em viagens & 7 & $1,2 \%$ \\
\hline Na criação de enredos & 4 & $0,7 \%$ \\
\hline $\begin{array}{l}\text { Ao ver o mundo de outra maneira/ampliação de } \\
\text { visão/perspectiva }\end{array}$ & 4 & $0,7 \%$ \\
\hline Nas comparações entre passado e presente & 4 & $0,7 \%$ \\
\hline No meu trabalho & 3 & $0,5 \%$ \\
\hline Ao aprender com os erros do passado & 2 & $0,3 \%$ \\
\hline Em entrevista de emprego & 2 & $0,3 \%$ \\
\hline Em atividades de entretenimento & 1 & $0,2 \%$ \\
\hline
\end{tabular}

Como é perceptível, as respostas foram bem distribuídas. Por se tratar de um ambiente escolar, o uso da história foi associado à função imediata de aprovação "Em certames, avaliações escolares, Exame Nacional do Ensino Médio": $26 \%$. Em termos práticos, essa poderia ter sido uma das serventias reconhecidas por todos os estudantes. Na sequência, a resposta mais frequente diz respeito à apropriação do conhecimento histórico "Em diálogos e debates com amigos e parentes", 16\%, o que demonstra, em certo sentido, o uso do saber escolar para o convívio em outros espaços. Já a compreensão de um assunto de história geral, do Brasil e/ou regional perfazem, juntos, 25,5\%. Não foi possível identificar se a importância atribuída a essa compreensão tem relação com questões pessoais, profissionais e/ou escolares, o que, sem dúvida, seria muito significativo. Além desses, o uso do conhecimento histórico para uma "autorreflexão" constitui um percentual razoável: 16,3\% (expressa nos itens "No aumento da consciência/conhecimento sobre o passado e/ou presente/ na formação de opinião sobre o mundo"; "Na tomada de posicionamento político"; "Ao ver o mundo de outra maneira/ampliação de visão/perspectiva”). Destaco, também, o alto índice de 7,9\% de estudantes do último ano da sua formação básica que não mencionaram um único caso em que o conhecimento histórico foi importante para eles. Assim como as outras questões abertas, a 
pergunta "Cite um caso em que o conhecimento da História foi importante para você" produziu respostas muito interessantes, que podem ser avaliadas à luz do contexto de cada escola e circunstância histórica.

Embora os resultados apresentados neste texto sejam parciais, porque relativos à perspectiva de estudantes, eles já propiciam reflexões sobre o ensino de história e suas serventias. É o que se percebe, por exemplo, ao levarmos em conta a importância atribuída a esta disciplina e os anseios dos educandos por mudanças metodológicas; ao analisarmos as funções da história em conhecer o passado em si e seu uso como ferramenta orientadora na vida prática; ou ao questionarmos o que falta para que o saber histórico seja mais atrativo a ponto de despertar o interesse por suas narrativas sem o comando docente, entre tantas outras questões suscitadas pelos dados. A simultânea trivialidade e profundidade dessas questões e suas respostas talvez demonstrem o quanto ainda há de ser feito.

\section{Ponderações e 1 conclusão}

Diante das informações apresentadas, é preciso ainda realizar quatro ponderações sobre essa pesquisa e seus resultados. A primeira delas diz respeito às dificuldades que uma investigação dessa natureza encontra e produz, como o processo de criação do questionário, que fomenta muitas dúvidas acerca do seu conteúdo, formato, linguagem, extensão, grau de abstração e nível de esforço exigido dos respondentes. Formular as perguntas "certas" é um procedimento hesitante e imprevisível. Mas não é só isso. Além dos problemas relativos ao questionário, há sempre muitas desconfianças que orbitam a recepção de um instrumento como esse, entre as quais: será que as respostas expressam, com precisão, as representações e práticas dos estudantes acerca dos temas inquiridos? Até que ponto as respostas não são concedidas em função de uma imagem que os estudantes têm sobre o que o pesquisador, os professores ou a escola esperam deles? Em que sentido as condições materiais do ambiente interferem nas respostas? Soma-se às dificuldades das fases de elaboração do questionário, coleta de dados e respostas propriamente ditas a etapa de 
sistematização dos resultados, cuja interpretação depende das ênfases dadas e das conexões estabelecidas ou não estabelecidas entre as respostas. Todos esses aspectos indicam que é preciso parcimônia em relação às informações geradas e, por conseguinte, certo coeficiente de desconfiança de um trabalho baseado predominantemente em dados quantitativos, assim como, obviamente, deve ser feito com qualquer outra pesquisa embasada em análise qualitativa. Independentemente da metodologia aplicada, a inconstância, a fugacidade e a imprevisibilidade do objeto exigem um receio saudável em relação aos resultados finais.

Uma segunda ponderação refere-se ao alcance dos resultados. Por mais que seja evidente, é importante mencionar que essa pesquisa não tem pretensões metonímicas: ela não é uma parte que representa o todo. As escolas públicas e particulares do município pesquisado têm culturas escolares específicas, que se fundem a questões ligadas à comunidade e famílias dos educandos, criando, assim, caracteres próprios. Por exemplo, a sugestão de aumentar a quantidade de aulas nas quais se faz uso de recurso audiovisual é menos frequente em escolas particulares, muito provavelmente porque os estudantes já têm acesso a esse dispositivo com maior recorrência. No que se refere especificamente à cultura histórica dos educandos (fator influente na visão sobre a disciplina escolar) (FLORES, 2007), é preciso considerar ainda a colonização da região, a maneira como as pessoas lidam com o seu passado e de que modo isso interfere no ensino formal da história. Ademais, sem pesquisas similares de outras regiões, é difícil afirmar ou infirmar o quanto os dados relativos ao município de Campo Mourão, PR, representam uma visão hegemônica sobre as funções do ensino de história e o quanto que há de idiossincrasias. Qual é, então, o grau de alcance de uma pesquisa como essa e por que executá-la? É difícil definir o alcance. A princípio, é o próprio objeto, com suas limitações espaciais, o que, por si só, seria um bom motivo para realizá-la. No entanto, existem outros dois importantes fatores que justificam a necessidade de trabalhos dessa natureza. $\mathrm{O}$ desenvolvimento de pesquisas similares poderá criar um banco de dados a partir do qual será possível executar comparações entre os resultados de diferentes 
regiões, e, com o passar dos anos, de diferentes datas. Além disso, pesquisas como esta funcionam como ponto de partida para reflexão, abertura ao diálogo e, obviamente, busca de soluções compartilhadas entre gestão escolar, professores, pais e estudantes. Ela gera, portanto, um processo de autorreflexão no professorado sobre seu ofício e público, que aumenta e refina o seu grau de (re)conhecimento acerca das representações, práticas, limitações, necessidades e possibilidades de mudança.

Terceira ponderação: por mais surpreendente e importante que possa ser, a exequibilidade das funções atribuídas ao ensino de história é assunto pouco debatido. Professores, alunos, pais e comunidade escolar de modo geral continuam a reproduzir atribuições supostamente óbvias ao ensino dessa disciplina. Apesar do reconhecimento das mudanças rápidas e profundas do mundo contemporâneo e do intenso debate acerca das possibilidades e limites cognitivos da historiografia, não se coloca em dúvida a exequibilidade das serventias dessa matéria, tampouco a própria necessidade de mantê-la no sistema escolar. Não me parece que essa situação seja resultado da imprescindibilidade em si dessa disciplina e menos ainda de que as respostas à pergunta para que serve a história tenham fundamentações consistentes. Da minha perspectiva, a ausência de problematização desse objeto reside, por um lado, na falta de questionamento e embasamento empírico que poderiam colocar em xeque as atribuições ao ensino de história presentes em documentos oficiais, nos manuais e nas falas de agentes da educação; e, por outro, em certa acomodação de quem realiza pesquisa na área, seja por que as respostas comumente aceitas concedem certo grau de legitimidade ao ensino de história, seja por que elas dispensam estratégias investigativas e metodológicas que reafirmam ou repensam as funções dessa matéria escolar.

Quarta e última ponderação: qualquer tentativa de detectar quais as funções do ensino de história terá resultados limitados. Ao que tudo indica, existem três modos de saber se as funções atribuídas ao ensino de história estão ou não sendo alcançadas. O primeiro é por meio de questionários, perguntando, explicitamente, às fontes (alunos, professores, materiais didáticos, documentos 
oficiais) sobre as funções da história na escola e fora dela, tal como realizado neste trabalho especificamente aos estudantes. As limitações desse tipo de pesquisa já foram mencionadas, e há outras ainda não sistematizadas. O segundo por meio de provas que aferem o grau cognitivo e de competência/ habilidade do estudante em lidar com o conteúdo programático. Por exemplo, com questões que objetivam identificar se houve capacidade de historicização, comparação, produção de conhecimento, articulação narrativa, análise conceitual, etc. E o terceiro modo é quando se afere a relação de conformidade entre o que é proferido (sobre as funções) e sua efetividade. Por exemplo: um aluno pode dizer que o ensino de história tem a função de aumentar sua tolerância com as minorias sociais (primeiro modo), pode responder questões que supostamente demonstram ser ele um indivíduo tolerante e que reconhece este valor como imprescindível (segundo modo), mas a prática cotidiana desse aluno (terceiro modo) pode ser muito diferente do que ele profere em um questionário e responde em uma prova escolar. Esse terceiro modo é impossível de se pesquisar, inacessível, portanto, aos procedimentos científicos.

Por fim, em que pese às dificuldades de pesquisa e as dúvidas que não se encerram com ela, considero que esse é um tipo de trabalho que precisa ser realizado, ampliado e aprofundado. A disciplina história está atravessando um questionamento público a seu respeito, muitas vezes infundado, outras nem tanto, mas sempre incômodo, o que não é, necessariamente, ruim. Uma das formas eficientes de responder a essa nova demanda é com pesquisa. O conhecimento histórico não é natural; o seu ensino também não o é (WINEBURG, 2001). Por isso, é necessário criar instrumental analítico para aferir, na medida do possível, o que se ensina em uma aula de história e contrastar esse tipo de informação com as funções atribuídas ao ensino de história de diferentes fontes: diretrizes educacionais, livros didáticos, professores, teóricos e filósofos da história, educadores e, não menos importante, a própria sociedade.

Os saberes históricos não são monopólio dos historiadores e, consequentemente, é preciso abrir o debate ao grande público. Se o esforço para 
que haja aprendizado histórico tem como ponto de partida o entendimento da especificidade do nosso próprio tempo, talvez seja hora de nos voltarmos com mais atenção à relação entre essa disciplina escolar e o momento em que vivemos, com fundamentação teórica, lógica e empírica. Afinal, só podemos afirmar que "as crianças não sabem história", ou que sabem, ou que sabem determinadas coisas da história e não outras, com pesquisa, muita pesquisa: a arma principal que temos necessidade e dever de portar.

\section{Referências}

BERBERT Jr., C. O. A história, a retórica e a crise dos paradigmas. 2 ed. Goiânia: CEGRAF-UFG, 2016.

BAROM, W.; CERRI, L. Identidade latino-americana e ideologia neoliberal. Práxis Educativa, Ponta Grossa, v. 13, n. 3, p. 713-733, set./dez. 2018.

CAIMI, F.; CERRI, L.; MISTURA, L. A força da cultura histórica: representações de estudantes brasileiros sobre heróis nacionais. Perspectiva: Revista do Centro de Ciências da Educação, v. 36, n. 4. p. 1357-1377, out./dez. 2018.

CALDERÓN, F.; CERRI, L.; ROSSO, A. Heróis e cultura histórica entre estudantes no Chile. Revista Brasileira de História, São Paulo, v. 36, n. 71, p. 179-201, 2016.

CERRI, L. F. Dados quantitativos na reflexão didática de estudantes e professores de História. Revista História Hoje, v. 5, n. 10, p. 138-158, 2016.

FLORES, E. C. Dos feitos e dos ditos: História e Cultura Histórica. Saeculum Revista de História, ano 13, n. 16. João Pessoa: Departamento de História/ Programa de Pós-Graduação em História/ UFPB, jan./ jun. 2007, p. 83-102.

FOUCAULT, M. A arqueologia do saber. 7 ed. Rio de Janeiro: Forense Universitária, 2008.

FOUCAULT, M. Arqueologia das ciências e história dos sistemas de pensamento. 3 ed. Rio de Janeiro: Forense Universitária, 2013.

GARDINER, P. Teorias da História. 5 ed. Lisboa: Fundação Calouste Gulbenkian, 2004. 
LIMA, L. C. A Narrativa na escrita da história e da ficção. In: LIMA, L. C. A Aguarrás do Tempo. Estudos sobre a narrativa. Rio de Janeiro: Editora Rocco, 1989. p. 15-111.

LYOTARD, J. F. O pós-moderno. São Paulo: Editora José Olympio, 1988.

MELLO, R. M. de. Ninguém ensina História... mas todo mundo aprende um pouco com ela: uma reflexão sobre as funções da História no Ensino Médio. História, Assis/Franca, v. 38, p. 11-24, 2019.

REIS, A. As concepções de jovens estudantes sobre assuntos históricos. Revista História Hoje, v. 8, n. 16, p. 70-89, 2019.

RÜSEN, J. Razão Histórica. Teoria da História: os fundamentos da ciência histórica. Brasília: UnB, 2001.

WHITE, H. Trópicos do discurso: ensaios sobre a crítica da cultura. Tradução Alípio Correia de Franca Neto. 2. ed. São Paulo: Editora da USP, 2001.

WHITE, H. Meta-história: a imaginação histórica do século XIX. 2. ed. São Paulo: Edusp, 1995.

WINEBURG, S. Historical Thinking and other unnatural acts: charting the future of teaching the past. Temple University Press: Philadelphia, 2001.

Recebido em: 12 de novembro de 2019

Aceito em: 27 de março de 2020 